\title{
Urban environments and objectively- assessed physical activity and sedentary time in older Belgian and Chinese community dwellers: potential pathways of influence and the moderating role of physical function
}

Ester Cerin ${ }^{1,2,3^{*}}$ (D), Delfien Van Dyck ${ }^{4,5}$, Casper J. P. Zhang ${ }^{2}$, Jelle Van Cauwenberg ${ }^{5,6}$, Poh-chin Lai $^{7}$ and Anthony Barnett ${ }^{1}$

\begin{abstract}
Background: Many studies have examined neighbourhood environmental correlates of older adults' physical activity (PA) but only a few focused on sedentary time (ST). Only a small proportion of these studies used objective measures of PA/ST, such as accelerometer-assessed PA/ST, and only a couple employed accelerometer cut-points appropriate for older adults. Furthermore, although older adults experience declines in physical function as they age, there is a dearth of information on the impact of the neighbourhood environment on PA/ST in individuals with different levels of physical function.

Methods: We used data from two extant cross-sectional studies conducted in Hong Kong (China) and Ghent (Belgium) $(N=829)$. Participants were recruited from pre-selected administrative units stratified by socio-economic status and walkability. Moderate-to-vigorous PA (MVPA) and ST were assessed for 7 days using accelerometers and cut-points developed for older adults. Objective neighbourhood environmental attributes within $400 \mathrm{~m}$ and $1 \mathrm{~km}$ buffers surrounding participants' homes were quantified using Geographic Information Systems data. Lower extremity physical function was objectively assessed. Socio-demographic information was collected via interviews. Total, direct and indirect (mediated) effects of environmental attributes on MVPA and ST were estimated using generalised additive mixed models and the joint-significant test.

(Continued on next page)
\end{abstract}

\footnotetext{
* Correspondence: Ester.Cerin@acu.edu.au

'Mary MacKillop Institute for Health Research, Australian Catholic University, Melbourne, Victoria, Australia

${ }^{2}$ School of Public Health, The University of Hong Kong, Hong Kong, Hong Kong SAR, China

Full list of author information is available at the end of the article
}

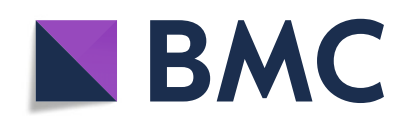

( ) The Author(s). 2020 Open Access This article is licensed under a Creative Commons Attribution 4.0 International License, which permits use, sharing, adaptation, distribution and reproduction in any medium or format, as long as you give appropriate credit to the original author(s) and the source, provide a link to the Creative Commons licence, and indicate if changes were made. The images or other third party material in this article are included in the article's Creative Commons licence, unless indicated otherwise in a credit line to the material. If material is not included in the article's Creative Commons licence and your intended use is not permitted by statutory regulation or exceeds the permitted use, you will need to obtain permission directly from the copyright holder. To view a copy of this licence, visit http://creativecommons.org/licenses/by/4.0/. The Creative Commons Public Domain Dedication waiver (http://creativecommons.org/publicdomain/zero/1.0/) applies to the data made available in this article, unless otherwise stated in a credit line to the data. 


\begin{abstract}
(Continued from previous page)
Results: Commercial/civic destination density and number of parks within $1 \mathrm{~km}$ from home showed positive total and direct effects on MVPA, and public transport density showed negative total and direct effects on ST, which were consistent across cities and physical function levels. The total and direct effects of residential density on MVPA depended on physical function, and those of residential density on ST differed by city. A complex network of potential inconsistent pathways linking all environmental attributes to MVPA and ST in the whole sample or in subgroups of participants was revealed.

Discussion: Access to parks and commercial/civic destinations appear to support older adults' MVPA in different geographical and cultural contexts and irrespective of their physical function level. By supporting MVPA, these characteristics also contribute to a reduction in ST. The potential effects of public transport, recreational facilities and residential density are less straightforward and point at inconsistent effects that may depend on the geographical context and level of physical function.
\end{abstract}

Keywords: Walkability, Accelerometry, Older adults, Europe, China, Neighbourhood environment, Sedentary time, Moderate-to-vigorous physical activity, Physical function

\section{Background}

A plethora of evidence suggests that regular engagement in moderate-intensity physical activity (PA) confers numerous health benefits to older adults, such as lower risk of cardiovascular disease, diabetes, cognitive decline and some types of cancer $[1,2]$. A smaller body of research also suggests that sedentary time (ST) - defined as any waking behaviour characterized by an energy expenditure $\leq 1.5$ METs (Metabolic Equivalents of Task) while in a sitting, reclining or lying posture [3] - is positively associated with all-cause mortality, lower cognitive function and a range of chronic conditions $[4,5]$.

To promote PA and reduce ST among ageing populations, it is important to create activity-friendly neighbourhoods [6, 7]. The characteristics of proximal neighbourhood environments are especially relevant to older adults who, due to declines in mobility, are particularly adversely impacted by environmental factors that discourage an active lifestyle [8]. Many studies have examined neighbourhood environmental correlates of PA in older adults $[9,10]$ whilst only a few have focused on sedentary behaviour [11-13]. In general, these studies indicate that living in neighbourhoods with good vs. poor access to commercial destinations, public transport, parks and recreational facilities is associated with higher levels of PA $[9,10]$ and somewhat less ST $[11,12]$.

Several shortcomings of published research on environmental correlates of older adults' PA, that also apply to ST, have been recently highlighted [9]. First, the great majority of studies employed self-report measures of PA and ST $[9,11]$ which may yield culturally-biased responses [14] and provide less accurate estimates of activity levels than their objective counterparts (e.g., accelerometers) [15]. The latter holds especially for older populations who are more likely to participate in lowerintensity PA and accumulate more ST, which can be difficult to report accurately [16]. Second, most studies that examined accelerometer-assessed moderate-tovigorous PA (MVPA) and ST employed cut-points that were developed for younger populations and, hence, likely underestimated the time that older adults spent in MVPA [9, 17] and overestimated ST [18]. Optimally, the estimation of older adults' MVPA via accelerometers should be based on cut-points appropriate for the age group such as those established by Barnett and colleagues [17] or Copeland and Esliger [19]. Third, there is a dearth of information on the moderating effects of lower extremity physical function on the environmentMVPA/ST relationships [9]. Balance difficulties and declining muscle strength with ageing result in changes in gait patterns and efficiency [20] that, in turn, increase the inter-individual variability in the relationship between accelerometer counts and walking speed [17]. Examining the moderating role of physical function is also important from a substantive viewpoint. In fact, there is some evidence that access to various destinations and amenities may have a greater impact on PA among older adults with mobility problems [12, 21-23]. However, only one of these studies employed accelerometers to measure PA [12] and none used accelerometer cut-points appropriate for older adults.

Limitations in the study design and analytical approaches have also been reported [9]. As the effect of the environment on PA is usually modest, to accurately characterize the shape of dose-response relationships, it is important to ensure a sufficient amount of variability in environmental exposures [24]. Several studies have achieved this by sampling from neighbourhoods with different environmental characteristics [12, 25-28]. However, most of these studies were conducted in single locations with limited variability in the built environment, while multi-country studies in adults [29-32] suggest that the pooling of comparable data from environmentally diverse cities and countries is needed to 
address the issues arising from insufficient variability in exposures.

Furthermore, previous studies employed analytical approaches that did not consider the potential causal pathways that link environmental characteristics with PA and ST, resulting in potentially biased or misinterpreted estimates of environmental-PA/ST associations [33]. For example, whilst residential density is a plausible precursor and, thus, a potential confounder of the effects of access to amenities and public transport on PA [34], most studies have failed to adjust for residential density [9]. Also, studies that mutually-adjusted for the effects of residential, public transport and/or amenity density on PA misinterpreted the regression coefficient of residential density as representing its total independent effect on PA, whilst this held true only for the regression coefficients of public transport and/or amenity density [35, 36]. An examination of potential causal pathways is also necessary to understand how specific environmental characteristics impact on older adults MVPA and ST. For example, residential density may impact on MVPA by increasing access to services and public transport that, in turn, may reduce car dependency and, thus, promote active transport $[8,11]$.

To address the above-mentioned limitations, this study examined the potential mediators of the relations between objectively-assessed characteristics of the neighbourhood environment and objectively-assessed MVPA and ST in older adults, and the moderating effects of lower extremity physical function. To achieve these objectives, pooled comparable data from two extant cross-sectional studies conducted in two urban locations with different levels of density - namely, Ghent (Belgium) and Hong Kong (China) - were used.

\section{Methods}

The Active Lifestyle and the Environment in Chinese Seniors (ALECS) [37] and Belgian Environmental Physical Activity Study on Seniors (BEPAS Seniors) [38] studies are observational epidemiologic cross-sectional studies conducted, respectively, in Hong Kong, China (2012-2016) and Ghent, Belgium (2010-2012). They both aimed to examine the relationships of neighbourhood environmental characteristics with physical activity, sedentary behaviours and health outcomes in older community dwellers and used comparable study design and measures. This study used information collected on ALECS $(n=402)$ and BEPAS $(n=427)$ participants who provided valid accelerometer data on PA and ST (total $N=829$ ).

\section{Participants}

Details about participant recruitment and selection for the ALECS [12, 21, 37] and BEPAS [38] studies have been described previously. Briefly, both studies employed a two-stage sampling strategy whereby participants were evenly recruited from pre-selected census administrative units (neighbourhoods) stratified by socioeconomic status (SES; median household income) and transportrelated walkability (a composite measure of dwelling density, street intersection density and land use mix) to maximise variability in environmental exposures (e.g., dwelling density, access to services, etc). Hong Kong participants were selected from 124 Tertiary Planning Units (TPUs), the smallest administrative units with publicly-available census-level data [37]. Ghent participants were selected from 20 neighbourhoods, each consisting of 1 to 5 adjacent statistical sectors, the smallest census administrative units for which socio-demographic data were available [38].

Due to privacy regulations restricting access to personal contact information, Hong Kong participants $(\geq 65$ years) were recruited in person from the Elderly Health Centres (EHCs) of the Department of Health (72\%) and from elderly community centres in the selected neighbourhoods (28\%). Eligibility criteria included being able to speak Cantonese, living in one of the selected neighbourhoods for at least six months, being able to walk unassisted for at least $10 \mathrm{~m}$ and being cognitively intact. Women and those living in more walkable neighbourhoods were more likely to consent participating in the study (all $p$ s <.001). A total of 909 participants were enrolled in the study ( $71 \%$ response rate). Of these, $\sim 45 \%$ (i.e., 416) were randomly selected to wear an accelerometer to objectively assess their PA and ST and 402 provided valid accelerometer data as defined in the Measures section below [37]. In Ghent, 1750 older adults ( $\geq 65$ years) were randomly selected from the statistical sectors and received an information letter through mail with a follow-up home visit approximately one week after receiving the letter. Eligibility criteria included being able to speak Dutch, living independently and able to walk $200 \mathrm{~m}$ without severe physical restrictions. A total of 508 participants were enrolled in the study (508 out of 1128 potential participants found at home after three attempts; $45 \%$ response rate). Of these, 427 participants provided valid accelerometer data. All participants provided written informed consent. Data were collected in the participants' homes in Ghent and in health/community centres in Hong Kong by trained interviewers. Sample characteristics are presented in Table 1.

\section{Measures}

\section{Neighbourhood environmental characteristics}

Participants' neighbourhoods were defined as $400 \mathrm{~m}$ and $1 \mathrm{~km}$-radius street-network buffers surrounding a participant's residential address. These distances are considered to be walkable as they correspond to an 
Table 1 Sample characteristics

\begin{tabular}{|c|c|c|c|}
\hline Characteristics [\% missing values] & $\begin{array}{l}\text { ALECS \& BEPAS } \\
(\mathrm{n}=829)\end{array}$ & $\begin{array}{l}\text { ALECS } \\
(n=402)\end{array}$ & $\begin{array}{l}\text { BEPAS } \\
(n=427)\end{array}$ \\
\hline \multicolumn{4}{|l|}{ Participant demographics and physical function } \\
\hline $\begin{array}{l}\text { Age (years; mean } \pm \mathrm{SD} \text { ) } \\
{[0.1 \% \text { missing }]}\end{array}$ & $74.83 \pm 6.18$ & $75.55 \pm 6.15$ & $74.16 \pm 6.14$ \\
\hline $\begin{array}{l}\text { Sex (\% female) } \\
{[0.1 \% \text { missing }]}\end{array}$ & 61.28 & 68.91 & 54.10 \\
\hline $\begin{array}{l}\text { Education (\% above primary school) } \\
{[0.1 \% \text { missing] }}\end{array}$ & 61.04 & 46.77 & 74.47 \\
\hline $\begin{array}{l}\text { Marital status (\% married or cohabiting) } \\
{[0.1 \% \text { missing }]}\end{array}$ & 64.66 & 62.94 & 66.28 \\
\hline $\begin{array}{l}\text { Neighbourhood SES (low/high, \% low) } \\
\text { [0.1\% missing] }\end{array}$ & 48.73 & 49.25 & 48.24 \\
\hline $\begin{array}{l}\text { Household car ownership (\% yes) } \\
{[0.2 \% \text { missing }]}\end{array}$ & 55.49 & 28.86 & 80.56 \\
\hline $\begin{array}{l}\text { SPPB (range 1-12, mean } \pm \text { SD) } \\
{[1.0 \% \text { missing }]}\end{array}$ & $10.03 \pm 1.94$ & $9.94 \pm 1.95$ & $10.11 \pm 1.93$ \\
\hline \multicolumn{4}{|l|}{$\begin{array}{l}\text { Objective neighbourhood attributes (mean } \pm \text { SD) } \\
{[0 \% \text { missing }]}\end{array}$} \\
\hline \multicolumn{4}{|l|}{ Residential density (dwellings/km²) } \\
\hline 400 m SNR buffers & $21,952 \pm 58,736$ & $37,227 \pm 81,358$ & $7569 \pm 6866$ \\
\hline $1 \mathrm{~km}$ SNR buffers & $21,546 \pm 21,211$ & $36,316 \pm 21,490$ & $7640 \pm 6328$ \\
\hline \multicolumn{4}{|l|}{ Commercial \& civic destination density (destinations $/ \mathrm{km}^{2}$ ) } \\
\hline 400 m SNR buffers & $155.74 \pm 140.61$ & $185.87 \pm 107.23$ & $127.38 \pm 161.07$ \\
\hline $1 \mathrm{~km}$ SNR buffers & $119.98 \pm 112.51$ & $118.27 \pm 60.33$ & $121.58 \pm 145.52$ \\
\hline \multicolumn{4}{|l|}{ Public transport density (stops $/ \mathrm{km}^{2}$ ) } \\
\hline 400 m SNR buffers & $16.56 \pm 17.38$ & $14.86 \pm 18.67$ & $18.16 \pm 15.92$ \\
\hline $1 \mathrm{~km}$ SNR buffers & $14.10 \pm 9.84$ & $10.74 \pm 6.87$ & $17.27 \pm 11.09$ \\
\hline \multicolumn{4}{|l|}{ Recreation density (facilities $/ \mathrm{km}^{2}$ ) } \\
\hline 400 m SNR buffers & $14.65 \pm 18.35$ & $19.61 \pm 23.83$ & $9.99 \pm 8.65$ \\
\hline $1 \mathrm{~km}$ SNR buffers & $14.36 \pm 13.35$ & $22.17 \pm 15.17$ & $7.00 \pm 4.23$ \\
\hline \multicolumn{4}{|l|}{ Park number } \\
\hline $400 \mathrm{~m}$ SNR buffers & $1.47 \pm 1.69$ & $1.21 \pm 1.46$ & $1.71 \pm 1.85$ \\
\hline $1 \mathrm{~km}$ SNR buffers & $7.15 \pm 6.24$ & $6.37 \pm 5.12$ & $7.88 \pm 7.07$ \\
\hline \multicolumn{4}{|l|}{$\begin{array}{l}\text { Accelerometer-assessed physical activity and } \\
\text { sedentary time (mean } \pm \text { SD) }[0 \% \text { missing] }\end{array}$} \\
\hline Moderate-to-vigorous physical activity (average min/day) & $55.78 \pm 37.05$ & $69.00 \pm 36.31$ & $43.33 \pm 34.24$ \\
\hline Sedentary time (average min/day) & $414.13 \pm 98.01$ & $404.94 \pm 98.11$ & $422.78 \pm 97.25$ \\
\hline Average wear time (average min/day) & $835.38 \pm 87.31$ & $811.71 \pm 92.22$ & $857.66 \pm 76.06$ \\
\hline
\end{tabular}

ALECS Active Lifestyle and the Environment in Chinese Seniors study, BEPAS Belgian Environmental Physical Activity Study on Seniors study, SD standard deviation, SES socio-economic status, SPPB Short Physical Performance Battery, SNR street-network residential

actual 10-20 min walk in any direction from home [12, 39]. Geographic Information Systems (GIS) data were used to quantify neighbourhood environment characteristics for each participant and each buffer size. Neighbourhood residential density (dwellings $/ \mathrm{km}^{2}$ ) was computed as a measure of urban densification. Other environmental attributes that were calculated included: number of parks contained within or intersected by a residential buffer; density of food and retail outlets (outlets $/ \mathrm{km}^{2}$ ); civic and institutional destinations (destinations $/ \mathrm{km}^{2}$ ); entertainment destinations (destinations $/ \mathrm{km}^{2}$ ); recreation density (destinations/ $\mathrm{km}^{2}$ ) and public transport density (stops $/ \mathrm{km}^{2}$ ). Given that densities of food, retail, entertainment, civic and institutional destinations were highly correlated in Ghent $(r>0.90)$, these measures were combined into a commercial and civic destination density variable 
(destinations $\left./ \mathrm{km}^{2}\right)$. Spatial analyses were conducted using ArcGIS (version 10.3; ESRI) software.

\section{Accelerometer-assessed moderate-to-vigorous physical activity and sedentary time}

MVPA and ST were objectively assessed using GT3X/ GT3X+ Actigraph accelerometers (Fort Walton Beach, FL, USA), which are valid and reliable tools to assess PA and ST in older adults $[19,40]$. Participants wore the accelerometer above the right hip for seven consecutive days during waking hours, except when engaging in water-based activities. Data were collected at 60-s epochs [41, 42] using the Low Frequency Extension (LFE) filter. Only vertical-axis data were analysed in the present study. Periods with $\geq 90$ min of consecutive zero accelerometer counts were categorized as non-wear time [43]. Days with at least $10 \mathrm{~h}$ of recorded wear time were considered valid. A participant was included in the analysis if s/he had at least five valid days of data, including at least one weekend day. MVPA and ST were defined using accelerometer cut points developed specifically for older adults and using the LFE filter. Specifically, values $<25 \mathrm{cpm}$ were categorised as ST [44] and values $\geq 1013$ cpm were categorised as MVPA [17].

\section{Covariates, mediators and moderators}

Information on participants' age, sex, educational attainment, marital status and household car ownership was collected using an interviewer-administered questionnaire. A dichotomous measure of neighbourhood-level
SES (high vs. low SES) was created using census data on administrative-level median household income. All variables were treated as covariates apart from household car ownership which was treated as a mediator of environment-MVPA/ST relationships. Physical function was quantified as the total score on the Short Physical Performance Battery (SPPB) [45]. The SPPB is a validated measure of lower extremity physical function with excellent metric characteristics. The total score on the SPPB and study site (Ghent vs Hong Kong) were considered as covariates and potential moderators of environment-car ownership- MVPA/ST associations.

\section{Statistical analyses and hypotheses}

Descriptive statistics were computed for all variables. As there were only 11 cases $(1.3 \%)$ with missing data on at least one variable, no multiple imputations were planned and the analyses were conducted on complete cases $(n=818)$.

This study aimed to identify neighbourhood environment characteristics potentially affecting older adults' MVPA and ST, mediators underlying these associations, the moderating role of physical function and the extent to which these associations were generalisable across study sites (Hong Kong and Ghent) (Fig. 1). Directed acyclic graphs were used to inform mediation analyses and the selection of a minimal sufficient set of confounders of exposure-mediator-outcome relationships (Additional file 1, Fig. S1). Exposure-mediator- outcome associations and the moderating effects of study site and

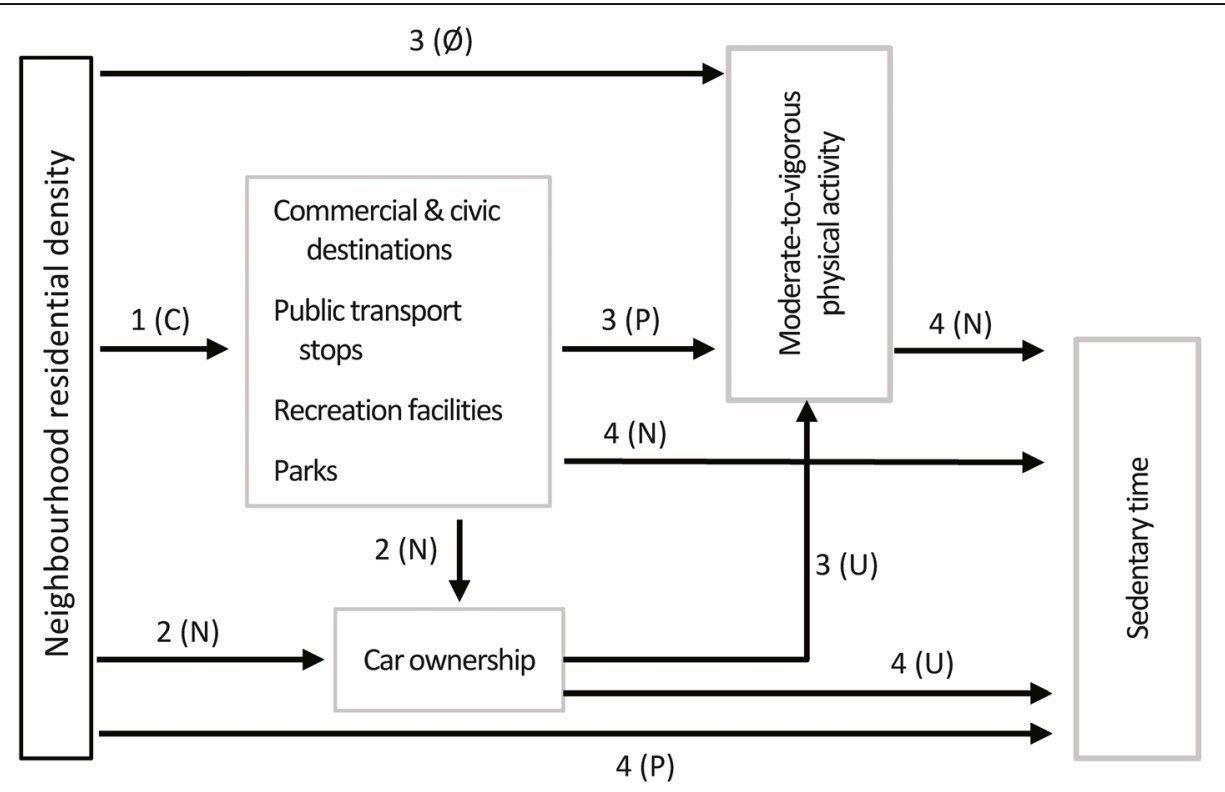

Fig. 1 Conceptual model of associations of neighbourhood environmental characteristics with moderate-to-vigorous physical activity and sedentary time. Pathways 1 to 4 indicate associations of environmental characteristics with moderate-to-vigorous physical activity and sedentary time mediated by car ownership and moderated by city (pathways 1-4) and physical function (pathways 2-4). N, P, $\varnothing$ and C indicate, respectively, hypothesised negative, positive, null and curvilinear relationships between variables. The letter $U$ indicate uncertain direction of association 
SPPB were estimated using generalized additive mixed models (GAMMs) [46] accounting for dependency in error terms due to area-level clustering (participants sampled from selected administrative units). GAMMs can model curvilinear relationships of unknown form, which allow the characterisation of dose-response relationships. Separate sets of GAMMs for neighbourhood attribute measures based on $400 \mathrm{~m}$ and $1 \mathrm{~km}$ residential buffers were estimated. Curvilinear associations were estimated using smooth terms modelled with thin plate splines [46]. If the data did not provide sufficient evidence of a curvilinear association, smooth terms were replaced by linear terms. Model selection (linear vs. curvilinear effect) was based on Akaike Information Criterion (AIC) values, where a lower AIC was indicative of a better-fitting model. $\mathrm{A} \geq 5$-unit difference in AIC was used as the criterion for model selection [31, 47]. Potential multicollinearity was assessed by computing the Variance Inflation Factor (VIF) for each variable included in the models. A VIF $>5$ was considered to be problematic.

\section{Total effects of neighbourhood environmental attributes on MVPA and ST}

Total effects refer to the mediated plus unmediated effects of an exposure (environmental variable) on the outcome (MVPA or ST). They are estimated by models that do not include potential mediators. The confounderadjusted total effects of neighbourhood environment characteristics on MVPA and ST and the moderating roles of SPPB and study sites were first estimated. Confounders included factors potentially associated with neighbourhood self-selection (choosing to live in neighbourhoods with specific characteristics) and MVPA/ST (see Fig. S1 and Supplementary information on Methods in Additional file 1). Residential density was included as a confounder of other environment-outcome relationships because it impacts on public transport and the availability of various destinations (Fig. 1) [48]. Study site and physical function (SPPB) were examined as moderators of environment-MVPA/ST associations by adding interaction terms to the main effect models. Significant moderation effects were probed by estimating associations for each study site and/or at three values of SPPB (mean and 1 standard deviation below and above the mean).

Based on previous studies, it was hypothesised that, in the whole sample, neighbourhood residential density would be unrelated to MVPA [9] but positively related to ST [49] (Fig. 1). MVPA was expected to be positively, and ST negatively, related to the densities of commercial and civic destinations, recreation facilities, public transport stops and number of parks in the neighbourhood $[9,11,49]$. SPPB was hypothesised to act as a moderator of the associations between density of commercial and civic destinations, recreation facilities, parks and MVPA $[12,21]$. Specifically, stronger positive associations between these characteristics and MVPA were expected in participants with worse physical function. No hypotheses were formulated regarding SPPB as a moderator of environment-ST associations and study site as a moderator of environment-MVPA/ST associations due to lack of findings in the literature.

\section{Mediation analyses of the effects of neighbourhood environmental attributes on MVPA and ST}

Mediation effects were examined using the jointsignificance test [50] and following the steps detailed in the Additional file 1. According to the joint-significance test, mediation is confirmed if the associations (regression coefficients) between an exposure and its mediator(s), and the exposure-adjusted associations between the mediator(s) and the outcome are statistically significant. The moderating role of study site was examined across all pathways linking environmental attributes with MVPA/ST, whilst the moderating role of SPPB was considered only for the direct effects of the environment on car ownership, MVPA and ST, and for the effects of car ownership on MVPA and ST. All analyses were conducted in $\mathrm{R}$ version 3.4.3 [51] using the packages 'mgcv' version 1.8.22 [46] and 'multcomp' version 1.4.8 [52]. Further details about the analyses are reported in the Additional file 1.

It was hypothesised that higher residential density would be positively related to public transport and various destination densities (Fig. 1) [48]. Unpublished data from a previous study conducted in Hong Kong suggested that these relationships might be curvilinear (inverted-U or concave down, increasing). Household car ownership was expected to be more prevalent among respondents living in areas with lower residential, commercial/civic destination, recreation and public transport densities [53]. We hypothesised that MVPA would be unrelated to residential density $[9,12]$ and positively associated with commercial and civic destinations, recreation facilities, public transport stops and number of parks [9]. No directional hypotheses were formulated about the main effects of car ownership on MVPA because of divergent findings in the literature [54-56]. Residential density was expected to be positively related [49], and other environmental attributes [11, 49] and MVPA [57] to be negatively related, to ST. No directional hypotheses were formulated about the direct effects of car ownership on ST because of divergent findings in the literature [55]. SPPB was expected to moderate the associations of car ownership $[55,58]$ with MVPA and ST (car ownership related to more MVPA and less ST in those with lower physical function), and public commercial/civic destinations, parks and recreation facilities with MVPA 
$[12,21]$ as explained above. No hypotheses were formulated regarding differences in effects across study sites.

\section{Results}

On average, participants accumulated 56 and 414 daily minutes of MVPA and ST, respectively, with Hong Kong older adults showing higher levels of activity than their Belgian counterparts (Table 1). The Belgian sample was more educated and had a markedly higher prevalence of household car ownership. Hong Kong neighbourhoods had higher residential and recreation densities than Ghent.

Total effects of neighbourhood environment attributes on MVPA and ST

Table 2 reports the total effects of neighbourhood environmental attributes on MVPA and ST. MVPA was positively associated with commercial/civic destination density and number of parks, whilst ST was negatively associated with public transport density within $1 \mathrm{~km}$ from home. SPPB moderated the associations between residential density and MVPA, whereby residential density was positively associated with MVPA only in older adults with below-average physical function (Table 3). Positive associations of commercial/civic destination and recreation densities with MVPA and of residential density with ST were only observed in Belgian older adults (Table 3 ).

\section{Direct and mediated effects of neighbourhood environmental attributes on MVPA and ST}

Figure 2 summarises the findings of the mediation analyses. Detailed model outputs (point estimates, 95\% CI and $p$-values for all regression coefficients) are presented in Tables S2-S5 (Additional file 1). Residential density within $400 \mathrm{~m}$ and $1 \mathrm{~km}$ residential buffers was found to have a direct positive effect on MVPA in older adults with below-average physical function $\left(\mathrm{e}^{b}\right.$ for $400 \mathrm{~m}=$ 1.004; 95\% CI: 1.000, 1.008; $p=.038$; $\mathrm{e}^{b}$ for $1 \mathrm{~km}=1.004$; 95\% CI: $1.000,1.009 ; p=.049)$ and on ST in older adults from Ghent ( $b$ for $400 \mathrm{~m}=1.65 ; 95 \% \mathrm{CI}$ : 0.25, 3.05; $p=.021 ; b$ for $1 \mathrm{~km}=2.79 ; 95 \% \mathrm{CI}: 0.71,4.87 ; p=.009$ ). The indirect effects of residential density on MVPA and ST through other environmental attributes and household car ownership were mixed. For example, $400 \mathrm{~m}$ buffer residential density showed a negative indirect effect on MVPA in Belgian older adults by being positively associated with public transport and recreation densities that, in turn, were negatively related to the odds of having a car in the household in all or only older adults with above-average physical function, and not having a car in the household was, in turn, predictive of less MVPA in Belgian older adults (Fig. 2 - panel A). In

Table 2 Total effects (associations) of neighbourhood environmental attributes on accelerometer-assessed daily minutes of moderate-to-vigorous physical activity (MVPA) and sedentary time (ST)

\begin{tabular}{|c|c|c|c|c|c|}
\hline \multirow[b]{2}{*}{ Environmental attribute } & \multirow[b]{2}{*}{ Buffer size } & \multicolumn{2}{|l|}{ MVPA (min/day) } & \multicolumn{2}{|l|}{ ST (min/day) } \\
\hline & & $\begin{array}{l}e^{b} \\
(95 \% \mathrm{Cl})\end{array}$ & $p$ & $\begin{array}{l}b \\
(95 \% \mathrm{Cl})\end{array}$ & $p$ \\
\hline \multirow[t]{2}{*}{ Residential density (1000 dwellings $/ \mathrm{km}^{2}$ ) } & $400 \mathrm{~m}$ & $\begin{array}{l}1.001^{\mathrm{a}} \\
(0.998,1.004)\end{array}$ & .455 & $\begin{array}{l}-0.07 \\
(-0.43,0.28)\end{array}$ & .688 \\
\hline & $1 \mathrm{~km}$ & $\begin{array}{l}1.002^{\mathrm{a}} \\
(0.999,1.006)\end{array}$ & .227 & $\begin{array}{l}-0.18^{b} \\
(-0.62,0.26)\end{array}$ & .418 \\
\hline \multirow[t]{2}{*}{$\begin{array}{l}\text { Commercial \& civic destination density } \\
\left(10 \text { destinations } / \mathrm{km}^{2} \text { ) }\right.\end{array}$} & $400 \mathrm{~m}$ & $\begin{array}{l}1.004^{\mathrm{b}} \\
(0.999,1.008)\end{array}$ & .098 & $\begin{array}{l}-0.21 \\
(-0.65,0.41)\end{array}$ & .651 \\
\hline & $1 \mathrm{~km}$ & $\begin{array}{l}1.009 \\
(1.003,1.015)\end{array}$ & .005 & $\begin{array}{l}-0.17 \\
(-1.31,0.96)\end{array}$ & .764 \\
\hline \multirow[t]{2}{*}{ Public transport density (stops $/ \mathrm{km}^{2}$ ) } & $400 \mathrm{~m}$ & $\begin{array}{l}0.999 \\
(0.997,1.002)\end{array}$ & .705 & $\begin{array}{l}0.26 \\
(-0.11,0.64)\end{array}$ & .172 \\
\hline & $1 \mathrm{~km}$ & $\begin{array}{l}1.002 \\
(0.995,1.009)\end{array}$ & .626 & $\begin{array}{l}-1.13 \\
(-2.16,-0.06)\end{array}$ & .048 \\
\hline \multirow[t]{2}{*}{ Recreation density (facilities $/ \mathrm{km}^{2}$ ) } & $400 \mathrm{~m}$ & $\begin{array}{l}1.002 \\
(0.999,1.005)\end{array}$ & .259 & $\begin{array}{l}0.03 \\
(-0.37,0.43)\end{array}$ & .889 \\
\hline & $1 \mathrm{~km}$ & $\begin{array}{l}1.004^{\mathrm{b}} \\
(0.999,1.009)\end{array}$ & .117 & $\begin{array}{l}-0.13 \\
(-0.74,0.48)\end{array}$ & .676 \\
\hline \multirow[t]{2}{*}{ Park number (parks in buffer) } & $400 \mathrm{~m}$ & $\begin{array}{l}0.991 \\
(0.961,1.023)\end{array}$ & .594 & $\begin{array}{l}1.71 \\
(-2.33,5.76)\end{array}$ & .406 \\
\hline & $1 \mathrm{~km}$ & $\begin{array}{l}1.017 \\
(1.006,1.028)\end{array}$ & .003 & $\begin{array}{l}0.21 \\
(-1.47,1.88)\end{array}$ & .809 \\
\hline
\end{tabular}

$\mathrm{e}^{b}$, exponentiated regression coefficient, $C l$ confidence intervals, $b$ regression coefficient, $p$ p-value. Models were adjusted for covariates listed in Table S1 (model T). ${ }^{a}$ moderated by physical function. ${ }^{b}$ moderated by study site 
Table 3 Significant moderators of total effects (associations) of neighbourhood environmental attributes on accelerometer-assessed MVPA and ST

\begin{tabular}{|c|c|c|c|}
\hline Interaction effect & $e^{b}$ & $95 \% \mathrm{Cl}$ & $p$ \\
\hline \multicolumn{4}{|l|}{ Outcome: $M V P A$} \\
\hline Residential density - $400 \mathrm{~m}$ buffer (1000 dwellings $/ \mathrm{km}^{2}$ ) by SPPB & 0.999 & $0.998,1.000$ & .015 \\
\hline Association at mean - 1 SD value of SPPB (8.08 points) & 1.004 & $1.000,1.007$ & .048 \\
\hline Association at mean value of SPPB (10.02 points) & 1.001 & $0.998,1.004$ & .531 \\
\hline Association at mean + 1 SD value of SPPB (11.96 points) & 0.998 & $0.995,1.002$ & .370 \\
\hline Residential density - $1 \mathrm{~km}$ buffer (1000 dwellings $/ \mathrm{km}^{2}$ ) by SPPB & 0.998 & $0.997,0.999$ & .003 \\
\hline Association at mean - 1 SD value of SPPB (8.08 points) & 1.006 & $1.002,1.010$ & .009 \\
\hline Association at mean value of SPPB (10.02 points) & 1.002 & $0.999,1.006$ & .219 \\
\hline Association at mean +1 SD value of SPPB (11.96 points) & 0.999 & $0.994,1.003$ & .582 \\
\hline $\begin{array}{l}\text { Commercial \& civic destination density - } 400 \mathrm{~m} \text { buffer } \\
\left(10 \text { destinations } / \mathrm{km}^{2}\right) \text { by Study site }\end{array}$ & 1.010 & $1.002,1.018$ & .017 \\
\hline Association in Hong Kong & 0.998 & $0.992,1.005$ & .613 \\
\hline Association in Ghent & 1.008 & $1.003,1.014$ & .004 \\
\hline Recreation density (facilities $/ \mathrm{km}^{2}$ ) $-1 \mathrm{~km}$ buffer by Study site & 1.027 & $1.004,1.050$ & .023 \\
\hline Association in Hong Kong & 1.002 & $0.997,1.007$ & .326 \\
\hline Association in Ghent & 1.029 & $1.007,1.052$ & .010 \\
\hline Outcome: sedentary time (average $\mathrm{min} /$ day) & $b$ & $95 \% \mathrm{Cl}$ & $p$ \\
\hline Residential density - $1 \mathrm{~km}$ buffer (1000 dwellings $/ \mathrm{km}^{2}$ ) by Study site & 2.52 & $0.14,4.90$ & .038 \\
\hline Association in Hong Kong & 0.00 & $-0.50,0.50$ & .953 \\
\hline Association in Ghent & 2.52 & $0.05,4.99$ & .046 \\
\hline
\end{tabular}

$\mathrm{e}^{b}$ exponentiated regression coefficient, $C l$ confidence intervals, $b$ regression coefficient, $p$ p-value, SPPB Short Physical Performance Battery, $400 \mathrm{~m}$ and 1 km buffers denote street-network residential buffer sizes. Models were adjusted for covariates listed in Table S1 (model T)

contrast, the indirect effects of $400 \mathrm{~m}$-buffer residential density on MVPA via commercial/civic destination density and household car ownership were curvilinear due to the curvilinear relationship between the two neighbourhood attributes (Fig. S2 - panels A and B). Specifically, an increase in residential density up to 15,000 dwellings/ $\mathrm{km}^{2}$ in Ghent was associated with an increase in the number of commercial/civic destinations which, after controlling for household car ownership, was positively associated with MVPA in Belgian older adults. However, further increases in residential density were associated with a decline in number of commercial/civic destinations (Fig. S2 - panel B), resulting in lower MVPA in Belgian older adults (Fig. 2 - panel A). Whilst 400 m-buffer commercial/civic destination density showed a positive direct effect on MVPA in the Belgian sample, its indirect effect mediated by household car ownership was negative since having more commercial/civic destinations was negatively associated with having a car and the latter was positively related to MVPA in Belgian older adults.

The indirect effects of $1 \mathrm{~km}$-buffer residential density and direct effects of other $1 \mathrm{~km}$-buffer environmental attributes on MVPA did not depend on study site (Fig. 2 panel B). The indirect effects of residential density on MVPA mediated by commercial/civic destination density and number of parks were positive. Household car ownership was a mediator of the associations of commercial/ civic destination and public transport stops/stations density with MVPA. These two environmental attributes were, respectively, positively and negatively related to having a car in the household in those with belowaverage physical function, and household car ownership was positively related to MVPA in the same subgroup of older adults.

As MVPA was negatively related to ST, all environmental attributes affecting MVPA also had an indirect effect on ST (through MVPA) but in the opposite direction (Fig. 2 panels $\mathrm{A}$ and $\mathrm{B}$ ). In addition to these pathways, a direct effect of $400 \mathrm{~m}$-buffer number of parks on ST moderated by physical function was observed. Older adults with below-average physical function accumulated more ST if they had a larger number of parks in their $400 \mathrm{~m}$ residential buffer, whilst the opposite held true for those with aboveaverage physical function (Fig. 2 - panel A). Additionally, 1 $\mathrm{km}$-buffer public transport density showed a negative direct effect on ST (Fig. 2 - panel B).

\section{Discussion}

Whilst a relatively large number of studies have examined objective neighbourhood environmental correlates 

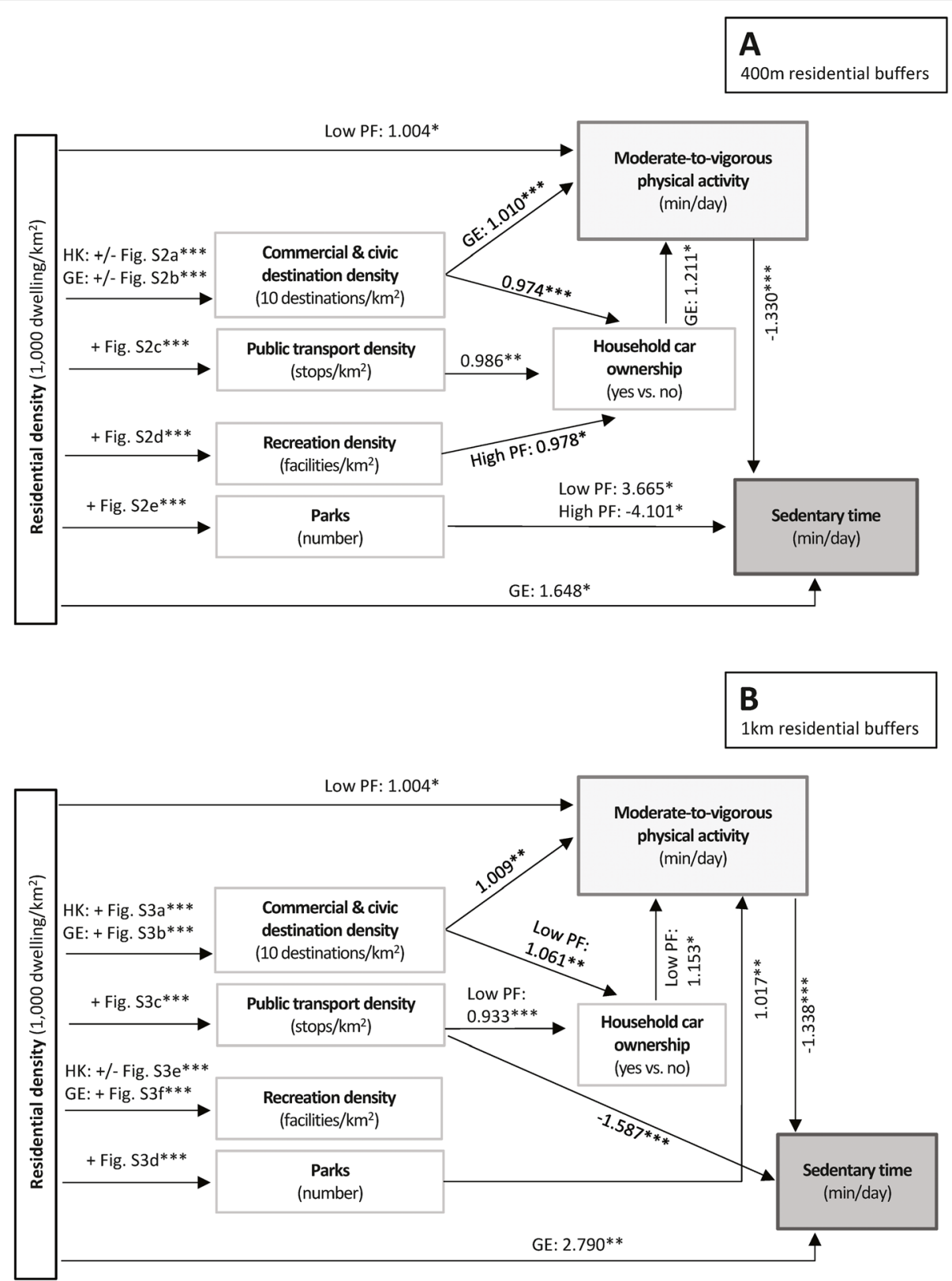

Fig. 2 Direct and indirect effects of neighbourhood environmental attributes on accelerometer-assessed moderate-to-vigorous physical activity and sedentary time. Panels $\mathbf{a}$ and $\mathbf{b}$ report the results for $400 \mathrm{~m}$ and $1 \mathrm{~km}$ street-network residential buffers, respectively. Only significant associations $(p<.05)$ are reported. Significant curvilinear associations between pairs of variables are labelled by their direction $(+$, positive; - , negative; + /-, positive and negative) and the figure number depicting them (e.g., Fig. S2a referring to Fig. S2 - panel A, representing the association between neighbourhood residential density and commercial and civic destination density within $400 \mathrm{~m}$ residential buffers). Values next to arrows pointing at 'Household car ownership', 'Moderate-to-vigorous physical activity' and 'Sedentary time' represent odds ratios, exponentiated regression coefficients and regression coefficients, respectively. Detailed results, point estimates and confidence intervals of all examined associations are reported in Tables S2-S5 and Figs. S2 and S3 included in the Additional file 1. ${ }^{*} p<.05 ;{ }^{* *} p<.01 ;{ }^{* * *} p<.001$

of older adults' PA, only a couple focused on accelerometerassessed MVPA defined using cut-points appropriate for this age group [9]. There is also a scarcity of studies on environmental correlates of older adults' accelerometer-assessed ST and on the moderating role of physical function. We addressed these knowledge gaps by pooling relevant comparable data collected in two culturally diverse populations living in two cities with remarkably different levels of residential density and car ownership, namely Hong Kong (China) and Ghent (Belgium).

Commercial/civic destination density and number of parks within $1 \mathrm{~km}$ from home were the only environmental 
attributes with significant positive total and direct effects on MVPA that were consistent across cities and older adults' physical function levels. A similar finding was observed for public transport density within $1 \mathrm{~km}$ from home with respect to ST. In contrast, the total and direct effects of residential density on MVPA depended on physical function, and those of residential density on ST depended on study site. Study site was also a moderator of the total effects of 1 $\mathrm{km}$-buffer recreation density and $400 \mathrm{~m}$-buffer commercial/civic destination density on MVPA. The analysis of direct and indirect effects of residential density and other environmental attributes on MVPA and ST revealed a complex network of potential inconsistent pathways of influence linking all environmental attributes to MVPA and ST in the whole sample or in subgroups of participants (e.g., Belgian older adults or older adults with belowaverage physical function).

\section{Neighbourhood environment and MVPA}

Availability and access to commercial destinations and services is one of the neighbourhood environmental features most consistently associated with PA in older adults $[8,9,59]$. Having access to shops, food outlets and other services promotes walking for transport [8], which has been found to contribute substantially to the accumulation of PA in older adults [38, 60, 61]. Thus, it is perhaps not surprising that, in the present study, commercial/civic destination density was equally positively associated with MVPA in Hong Kong as well as Belgian older adults irrespective of their level of physical function. Whilst, in essence, this finding is not new, it is noteworthy that the present study accounted for the potential confounding effects of residential density, while previous studies did not [12, 62, 63]. It is important to adjust for residential density because increases in population density do not only lead to increases in amenities. They also provide more opportunities for social contacts. With a larger social network, older adults are more likely to accrue more MVPA by walking to/from other individuals' homes, which are among the most frequently reported walking destinations in this age group [64, 65]. It is interesting that whilst a positive association between $1 \mathrm{~km}$-buffer commercial/civic destination density and MVPA was observed in both cities, this was not the case for the same environmental indicator based on $400 \mathrm{~m}$ radius residential buffers. Sufficient evidence for a positive association was found in the Belgian sample only. This may be in part due to Hong Kong older adults being more physically active (with 60\% more MVPA than Belgian older adults in this study) and generally accumulating greater volumes of transportation walking than their Belgian counterparts [21, 38, 66, 67] which, in turn, would make them more willing to walk further than 400 $\mathrm{m}$ from home for errands. Studies with data on older adults' mobility behaviour and activity locations would be needed to test these hypotheses.

Access to parks and recreation facilities are neighbourhood environmental features that have been previously linked to higher levels of total PA [9], transportation walking [8] and leisure-time PA [10] among older adults. In line with these findings, we observed a positive association between the number of parks within $1 \mathrm{~km}$ from home and MVPA in both cities, irrespective of the level of physical function. In contrast, recreation density was positively related to MVPA only in Belgian older adults. An earlier study on Hong Kong older adults had found a positive association between recreation density and accelerometer-assessed MVPA [12]. However, that study used a much higher accelerometer cut-point to identify time spent in MVPA which might have captured vigorous PA (e.g., exercising in a gym) and missed a large proportion of moderate-intensity activities, such as walking. This would have yielded an inflated association between recreation density and MVPA. Though a high proportion of Hong Kong older adults engage in leisuretime PA other than walking [68], these activities are not particularly vigorous [68] and are likely performed in parks, sport fields and free-of-charge community and senior centres rather than commercial gyms and recreation/sport centres [69]. This may be one of the reasons why this study did not find an association between recreation density and MVPA in Hong Kong older adults.

Recent systematic reviews reported strong evidence of a positive association between access/availability of public transport and self-reported PA [9], transportation walking [9] and leisure-time walking within the neighbourhood [10]. In contrast, this study failed to observe a significant total main effect of public transport density on accelerometer-assessed MVPA. In line with our findings, Barnett and colleagues [9] also reported no evidence of an association between public transport and objectively-assessed PA. Although having good access to affordable public transport may promote walking to/ from public transport stops and walking outside the neighbourhood, especially among older adults without a car, it may also reduce the amount of walking to/from other destinations in the neighbourhood [70] and, thus, yield no gain in PA. Studies assessing activity locations via GPS units, smartphones or web-assisted interviews would be required to verify the validity of these hypotheses.

The present study also found negative indirect effects of public transport density on MVPA mediated by household car ownership. Specifically, as expected, older adults living in a neighbourhood with high public transport density were less likely to own a car [70]. However, not having a car in the household was associated with less rather than more MVPA in Belgian older adults and those with below-average physical function. Similarly, 
two studies in the UK reported higher levels of objectivelyassessed PA in older drivers vs. non-drivers $[55,71]$, which has been attributed to cars providing the extra support that older adults with mobility or health problems need to maintain their active lifestyle and interaction with the community [71]. Yet, this supposition may apply only to locations where car ownership and driving is highly prevalent among older adults, such as Western countries.

Whilst, as hypothesised, no significant total main effect of residential density on MVPA was observed, positive total and direct effects were found in older adults with below-average physical function. As noted earlier, densely-populated neighbourhoods provide plentiful opportunities for social interaction, a greater variety of amenities and shorter distances between destinations than low-density neighbourhoods. These attributes are particularly important to mobility-impaired older adults who, although less likely to engage in recreational PA [72], may continue to walk for utilitarian purposes in their local community. Whilst a few other studies have also found stronger positive associations between overall access to services and PA in mobility-impaired vs. nonimpaired older adults [21, 22], the overall results are mixed [9] warranting further investigation.

Apart from finding positive direct effects of residential density on MVPA in participants with lower physical function, this study uncovered several inconsistent indirect effects mediated by other environmental attributes and household car ownership. When considering environmental attributes within $400 \mathrm{~m}$ from home, residential density had a positive indirect effect on MVPA via commercial/civic destination density, and negative indirect effects via commercial/civic destination, public transport and recreation density through household car ownership in Belgian older adults. The negative indirect effects were due to various amenity densities being negatively related to the likelihood of having a car in the household and, as noted earlier, having a car in the household being associated with more MVPA in Belgian older adults. Whilst the positive association between car ownership and MVPA has been discussed earlier, here it is worth commenting on the possible reasons for observing a negative association between recreation density and car ownership only in older adults with above-average physical function. Recreational facilities are more relevant to healthy and mobile individuals able to participate in sports and exercise than to those with impaired physical function $[22,72]$. Hence, easy access to recreational facilities from home may be a stronger motivator for not owning a car among fully mobile older adults, which is another hypothesis that needs to be evaluated in future studies.

The indirect effects of residential density within $1 \mathrm{~km}$ residential buffers on MVPA were more positive than those observed for the smaller residential buffers and extended to both cities (Fig. 2). Only one negative indirect effect was observed via public transport density and car ownership in mobility-impaired older adults. In this regard, it is unclear why commercial/civic destination density was associated with a higher likelihood of car ownership in those with mobility impairment. One reason could be the higher levels of traffic and crowdedness typically found in such locations which may deter active transportation in this group of older adults.

\section{Neighbourhood environment and ST}

Although only public transport and residential densities showed significant total and direct effects on ST, one of which held true only for the Belgian sample, all environmental attributes affecting MVPA had also an indirect, but reverse, effect on ST. This is because a negative association was observed between MVPA and ST. The actual effects of neighbourhood characteristics deemed to provide opportunities for an active lifestyle on PA are usually small [24]. This is even more the case for ST as the effects of the environment may be, in this case, channelled through PA and, thus, even more distal (see Fig. 1). Under such a scenario and the presence of inconsistent mediating mechanisms, it is understandable that, despite the scarcity of significant total effects, a considerable number of indirect effects of environmental attributes on ST were found [73, 74]. These findings suggest that activity-friendly environments may help older adults replace ST with MVPA.

Negative total and direct effects of public transport density on ST were observed in both cities and across people with different levels of physical function. Public transport density is a measure of regional accessibility [75] particularly relevant to residents with amenity-poor neighbourhoods. It may promote short utilitarian walking trips which, in this age group, are often of light-to-moderate intensity [12] and, hence, may be reflected in lower levels of ST rather than higher levels of MVPA [12, 42]. Parks within $400 \mathrm{~m}$ from home also exerted a direct effect on ST, which was moderated by physical function. In contrast, as noted earlier, the number of parks within $1 \mathrm{~km}$ from home had a positive effect on MVPA. Older adults may leisurely stroll to/from parks close to home (i.e., within $400 \mathrm{~m}$ from home) and walk faster to/from parks further away from home to compensate for the time cost of their trip. After reaching their destination, mobilityimpaired individuals may prefer spending their time sitting and socialising in the park, whilst their counterparts may prefer strolling around the park.

Finally, a total and direct positive effect of residential density on ST was observed only in Belgian older adults. This latter finding mirrors those of international studies in adults [76]. Differences in housing between Ghent and Hong Kong may be responsible for the observed 
difference in associations. High-density European urban areas are typified by multi-storey residential buildings with relatively small apartments, whilst low-density areas are characterised by larger detached houses where older adults have more opportunities to engage in gardening and housework and, hence, reduce the time they spend in sedentary activities. In contrast, in Hong Kong, apartments are typically small throughout the whole territory and detached houses with gardens are very rare and unaffordable to older adults.

\section{Limitations}

Several limitations need to be considered in interpreting the findings of this study. First, this study is cross-sectional. Hence, evidence of causality to support policy changes and environmental interventions is limited. Second, the findings from these two cities may not be generalisable to other geographical locations, especially low-middle income countries [77]. Third, the sampling strategy was designed to maximise the variability of environmental attributes within the cities. Therefore, the samples may not be representative of the populations of older adults in the two cities. Fourth, eligibility criteria for participation in the study included the ability to walk without assistance for a short distance without major difficulties. Thus, the findings apply to older adults with moderate-to-high mobility levels. Fifth, the eligibility criterion related to the ability to walk without assistance differed across the two study sites. However, fortunately, the between-site difference in average SPPB scores was minimal (0.17 points). Sixth, data on activity locations was not collected. It would have been useful and informative to distinguish between MVPA/ST accumulated within vs. outside the $400 \mathrm{~m}$ and $1 \mathrm{~km}$ residential buffers to better understand the impact of the neighbourhood environment on MVPA/ST in older adults. However, collection of location data via Global Positioning System (GPS) devices is challenging in ultra-dense cities like Hong Kong [78]. Seventh, as the response rate in the two cities differed $(71 \%$ vs $45 \%)$ the degree of sampling bias might have also differed and contributed to the observed moderating effects of study site. Finally, this study treated car ownership as a potential mediator of environment-MVPA/ST associations, while it could have also been considered as a factor influencing neighbourhood self-selection (i.e., a confounder). As older adults typically have lower income than their younger counterparts, they are less likely to afford living in their preferred type of neighbourhood. This is especially the case in Hong Kong [12]. Hence, in this study, it seemed more reasonable to consider car ownership as a mediator.

\section{Conclusions}

As evidenced in this study, an analysis of potential pathways through which specific neighbourhood environmental attributes affect older adults' PA and ST can reveal competing influences that remain concealed when considering only the total effects of the environment on PA and ST. The revelation of competing mechanisms is important for the development of effective environmental interventions. This study suggests that, in general, neighbourhood characteristics that support MVPA also reduce ST by helping older adults replace ST with MVPA. These neighbourhood characteristics are parks and commercial and civic destinations within $1 \mathrm{~km}$ from home. They were found to be equally relevant to Hong Kong and Belgian older adults with different levels of physical function. Public transport and recreational facilities appear to have a negative impact on MVPA by reducing the likelihood of car ownership, but only in subgroups of older adults. The fact that car ownership may be necessary to maintain a certain level of MVPA in some suggests that the affordability, frequency, comfort and intelligibility of the current public transport systems may be inadequate for an ageing population, as was recently noted in a qualitative study of Chinese older adults in Melbourne [79]. Yet, the present study also suggests that public transport may help older adults to reduce ST irrespective of geographical location and physical function level. Finally, this study also revealed an intricate network of contrasting linear and curvilinear pathways of influence of residential density on MVPA and ST, which partly depended on the geographical context and individual physical function. Urban densification can lead to positive and negative impacts on older adults' levels of activity. By identifying and strengthening the context-specific pathways that support MVPA and minimising or mitigating those that discourage it, we can create cities that can sustainably support healthy and active ageing.

\section{Supplementary information}

Supplementary information accompanies this paper at https://doi.org/10. 1186/s12966-020-00979-8.

\footnotetext{
Additional file 1: Supplementary Information on Methods including (in order of appearance): Figure S1. Directed acyclic graph depicting the hypothesised relations between neighbourhood residential density, other environmental attributes, household car ownership, covariates and outcome variables (moderate-to-vigorous physical activity and sedentary time). Detailed description of statistical analyses (generalised additive mixed models and mediation analyses) and hypotheses. Table S1. Outline of regression analyses. Supplementary Results including (in order of appearance): Direct and mediated effects of neighbourhood environmental attributes on MVPA and ST. Table S2. Step 1: Direct effects of neighbourhood residential density on other environmental attributes [pathways 1 in Fig. 1]. Figure S2. Shape of significant nonlinear relationships of residential density with environment attributes (400 m street-network residential buffers). Figure S3. Shape of significant nonlinear relationships of residential density with environment attributes (1 km street-network residential buffers). Table S3. Step 2: Direct effects of neighbourhood environmental attributes on household car ownership (ref: no car) [pathways 2 in Fig. 1]. Table S4. Step 3: Direct effects of neighbourhood environmental attributes and household car ownership on MVPA [pathways 3 in Fig. 1]. Table S5. Step 4: Direct effects of neighbourhood environmental attributes, household car ownership and MVPA on sedentary time [pathways 3 in Fig. 1].
} 


\section{Abbreviations}

AIC: Akaike Information Criterion; ALECS: Active Lifestyle and the Environment in Chinese Seniors; BEPAS: Belgian Environmental Physical Activity Study; EHCs: Elderly Health Centres; GAMMs: Generalised Additive Mixed Models; GIS: Geographic Information Systems; GPS: Global Positioning System; LFE: low-frequency filter; METs: Metabolic Equivalents of Task; MVPA: moderate-to-vigorous physical activity; PA: physical activity; SD: standard deviation; SES: socio-economic status; SNR: street-network residential; SPPB: Short Physical Performance Battery; ST: sedentary time; TPUs: Tertiary Planning Units; VIF: variance inflation factor

\section{Acknowledgements}

The authors would like to thank Sien Benoit and Tim Baert for calculating the GIS variables for BEPAS Seniors.

\section{Authors' contributions}

EC (Hong Kong study) conceptualised the paper, coordinated the study, secured funding, conducted the statistical analyses and wrote the manuscript. DVD (Belgian study) processed accelerometer data, revised the article for important intellectual content. CJPZ (Hong Kong study) coordinated the study, collected the data, computed the Geographic Information Systems (GIS) measures, curated the data and revised the article for important intellectual content. JVC (Belgian study) contributed to the design of the study and data collection, and revised the article for important intellectual content. PCL (Hong Kong study) secured funding, coordinated the GIS analyses, curated the GIS data and revised the article for important intellectual content. AB (Hong Kong study) secured funding, contributed to the writing of parts of the manuscript and revised the article for important intellectual content. The authors read and approved the final manuscript.

\section{Funding}

This work was supported by a General Research Fund grant from the University Grant Committee, Hong Kong [grant number: HKU $741511 \mathrm{H}$ ] and by Research Foundation Flanders [project number B/13018/01]. Cerin was supported by an Australian Research Council Future Fellowship [grant number: FT14010085]. Van Dyck and Van Cauwenberg were supported by Research Foundation Flanders [grant numbers FWO12/PDO/158 and FWO1211117]. The funding bodies had no roles in the design of the studies, interpretation of data, decision to publish or writing of the manuscript.

\section{Availability of data and materials}

Due to lack of consent to share data outside the team of investigators, individual data cannot be made accessible.

\section{Ethics approval and consent to participate}

The Active Lifestyle and the Environment in Chinese Seniors (ALECS) project was approved by the ethics committee of the Department of Health (Hong Kong Special Administrative Region, Hong Kong Special Administrative Region) and the University of Hong Kong Research Ethics Committee for Non-Clinical Faculties (ethics approval no.: EA27021), while the Belgian Environmental Physical Activity Study on Seniors (BEPAS Seniors) was approved by the Ethics Committee of the Ghent University Hospital (ethics approval no.: B670201423000). The studies were performed in agreement with the Helsinki declaration and its amendments, and in accordance with local legislations. All participants provided signed informed consent before participation in the studies.

\section{Consent for publication}

Not applicable.

\section{Competing interests}

The authors declare that they have no conflict of interest.

\section{Author details}

${ }^{1}$ Mary Mackillop Institute for Health Research, Australian Catholic University, Melbourne, Victoria, Australia. ${ }^{2}$ School of Public Health, The University of Hong Kong, Hong Kong, Hong Kong SAR, China. ${ }^{3}$ Baker IDI Heart and Diabetes Institute, Melbourne, Victoria, Australia. ${ }^{4}$ Department of Movement and Sport Sciences, Faculty of Medicine and Health Sciences, Ghent University, Ghent, Belgium. ${ }^{5}$ Research Foundation Flanders (FWO), Brussels, Belgium. ${ }^{6}$ Department of Public Health and Primary Care, Faculty of Medicine and Health Sciences, Ghent University, Ghent, Belgium. ${ }^{7}$ Department of Geography, Faculty of Social Sciences, The University of Hong Kong, Hong Kong, Hong Kong SAR, China.

Received: 31 March 2020 Accepted: 4 June 2020

Published online: 09 June 2020

\section{References}

1. Lee IM, Shiroma EJ, Lobelo F, Puska P, Blair SN, Katzmarzyk PT. Effect of physical inactivity on major non-communicable diseases worldwide: an analysis of burden of disease and life expectancy. Lancet. 2012;380(9838): 219-29.

2. Vogel T, Brechat PH, Lepretre PM, Kaltenbach G, Berthel M, Lonsdorfer J. Health benefits of physical activity in older patients: a review. Int J Clin Pract. 2009:63(2):303-20.

3. Tremblay MS, Aubert S, Barnes JD, Saunders TJ, Carson V, Latimer-Cheung $A E$, et al. Sedentary behavior research network (SBRN) - terminology consensus project process and outcome. Int J Behav Nutr Phys Act. 2017; 14(1):75.

4. de Rezende LF, Rey-Lopez JP, Matsudo VK, do Carmo Luiz O. Sedentary behavior and health outcomes among older adults: a systematic review. BMC Public Health 2014:14:333.

5. Steinberg SI, Sammel MD, Harel BT, Schembri A, Policastro C, Bogner HR, et al. Exercise, sedentary pastimes, and cognitive performance in healthy older adults. Am J Alzheimers Dis Other Dement. 2015;30(3):290-8.

6. World Health Organisation. Global age-friendly cities: a guide. Geneva: WHO 2007. Available from: http://www.who.int/ageing/publications/Global_age_ friendly_cities_Guide_English.pdf.

7. World Health Organisation. Global action plan for the prevention and control of noncommunicable diseases 2013-2020. Geneva: WHO; 2013.

8. Cerin E, Nathan A, Van Cauwenberg J, Barnett DW, Barnett A. The neighbourhood physical environment and active travel in older adults: a systematic review and meta-analysis. Int J Behav Nutr Phys Act. 2017;14(1):15.

9. Barnett DW, Barnett A, Nathan A, Van Cauwenberg J, Cerin E. Built environmental correlates of older adults' total physical activity and walking: a systematic review and meta-analysis. Int J Behav Nutr Phys Act. 2017;14(1):103

10. Van Cauwenberg J, Nathan A, Barnett A, Barnett DW, Cerin E. Relationships between neighbourhood physical environmental attributes and older adults' leisure-time physical activity: a systematic review and meta-analysis. Sports Med. 2018;48(7):1635-60.

11. Barnett A, Cerin E, Ching CSK, Johnston JM, Lee RSY. Neighbourhood environment, sitting time and motorised transport in older adults: a crosssectional study in Hong Kong. BMJ Open. 2015;5(4):e007557.

12. Cerin E, Zhang CJ, Barnett A, Sit CH, Cheung MM, Johnston JM, et al. Associations of objectively-assessed neighborhood characteristics with older adults' total physical activity and sedentary time in an ultra-dense urban environment: findings from the ALECS study. Health Place. 2016;42:1-10.

13. Shaw RJ, Čukić I, Deary IJ, Gale CR, Chastin SFM, Dall PM, et al. The influence of neighbourhoods and the social environment on sedentary behaviour in older adults in three prospective cohorts. Int J Environ Res Public Health. 2017:14(6):557.

14. Cerin E, Cain KL, Oyeyemi AL, Owen N, Conway TL, Cochrane T, et al. Correlates of agreement between accelerometry and self-reported physical activity. Med Sci Sports Exerc. 2016;48(6):1075-84.

15. Aguilar-Farias N, Hopman-Rock M. Measurement of physical activity among older people. In: Nyman SR, Barker A, Haines T, Horton K, Musselwhite C, Peeters G, et al., editors. The Palgrave Handbook of Ageing and Physical Activity Promotion. Cham: Palgrave Macmillan; 2018. p. 631-52.

16. Dipietro L, Caspersen CJ, Ostfeld AM, Nadel ER. A survey for assessing physical activity among older adults. Med Sci Sports Exerc. 1993;25(5): 628-42.

17. Barnett A, van den Hoek D, Barnett D, Cerin E. Measuring moderateintensity walking in older adults using the ActiGraph accelerometer. BMC Geriatr. 2016:16(1):211.

18. Heesch KC, Hill RL, Aguilar-Farias N, van Uffelen JGZ, Pavey T. Validity of objective methods for measuring sedentary behaviour in older adults: a systematic review. Int J Behav Nutr Phys Act. 2018;15(1):119.

19. Copeland JL, Esliger DW. Accelerometer assessment of physical activity in active, healthy older adults. J Aging Phys Act. 2009;17(1):17-30. 
20. Ko SU, Stenholm S, Metter EJ, Ferrucci L. Age-associated gait patterns and the role of lower extremity strength - results from the Baltimore longitudinal study of aging. Arch Gerontol Geriatr. 2012;55(2):474-9.

21. Barnett A, Cerin E, Zhang CJP, Sit CHP, Johnston JM, Cheung MMC, et al. Associations between the neighbourhood environment characteristics and physical activity in older adults with specific types of chronic conditions: the ALECS cross-sectional study. Int J Behav Nutr Phys Act. 2016;13:53.

22. Gallagher NA, Clarke PJ, Ronis DL, Cherry CL, Nyquist L, Gretebeck KA. Influences on neighborhood walking in older adults. Res Gerontol Nurs. 2012;5(4):238-50.

23. Satariano WA, Ivey SL, Kurtovich E, Kealey M, Hubbard AE, Bayles CM, et al. Lower-body function, neighborhoods, and walking in an older population. Am J Prev Med. 2010;38(4):419-28.

24. Kerr J, Sallis JF, Owen N, De Bourdeaudhuij I, Cerin E, Sugiyama T, et al. Advancing science and policy through a coordinated international study of physical activity and built environments: IPEN adult methods. J Phys Act Health. 2013;10(4):581-601.

25. Carlson JA, Bracy NL, Sallis JF, Millstein RA, Saelens BE, Kerr J, et al. Sociodemographic moderators of relations of neighborhood safety to physical activity. Med Sci Sports Exerc. 2014;46(8):1554-63.

26. Cerin E, Mellecker R, Macfarlane DJ, Barnett A, Cheung MC, Sit CH, et al. Socioeconomic status, neighborhood characteristics, and walking within the neighborhood among older Hong Kong Chinese. J Aging Health. 2013; 25(8):1425-44

27. Nathan A, Wood L, Giles-Corti B. Perceptions of the built environment and associations with walking among retirement village residents. Environ Behav. 2012:46(1):46-69.

28. Van Holle V, Van Cauwenberg J, Gheysen F, Van Dyck D, Deforche B, Van de Weghe $\mathrm{N}$, et al. The association between Belgian older adults' physical functioning and physical activity: what is the moderating role of the physical environment? PLoS One. 2016;11(2):e0148398.

29. Cerin E, Cain KL, Conway TL, Van Dyck D, Hinckson E, Schipperijn J, et al. Neighborhood environments and objectively measured physical activity in 11 countries. Med Sci Sports Exerc. 2014;46(12):2253-64.

30. Cerin E, Mitas J, Cain KL, Conway TL, Adams MA, Schofield G, et al. Do associations between objectively-assessed physical activity and neighbourhood environment attributes vary by time of the day and day of the week? IPEN adult study. Int J Behav Nutr Phys Act. 2017;14(1):34.

31. Cerin E, Conway TL, Adams MA, Barnett A, Cain KL, Owen N, et al. Objectively-assessed neighbourhood destination accessibility and physical activity in adults from 10 countries: an analysis of moderators and perceptions as mediators. Soc Sci Med. 2018;211:282-93.

32. Sallis JF, Cerin E, Conway TL, Adams MA, Frank LD, Pratt M, et al. Physical activity in relation to urban environments in 14 cities worldwide: a crosssectional study. Lancet. 2016;387(10034):2207-17.

33. Fleischer NL, Diez Roux AV. Using directed acyclic graphs to guide analyses of neighbourhood health effects: an introduction. J Epidemiol Community Health. 2008;62(9):842-6.

34. Frank LD, Engelke PE, Schmid TL. Health and community design: the impacts of the built environment on physical activity. Washington, DC: Island Press; 2003.

35. Hanibuchi T, Kawachi I, Nakaya T, Hirai H, Kondo K. Neighborhood built environment and physical activity of Japanese older adults: results from the Aichi Gerontological evaluation study (AGES). BMC Public Health. 2011;11:657.

36. King AC, Toobert D, Ahn D, Resnicow K, Coday M, Riebe D, et al. Perceived environments as physical activity correlates and moderators of intervention in five studies. Am J Health Promot. 2006;21(1):24-35.

37. Cerin E, Sit CH, Zhang CJ, Barnett A, Cheung MM, Lai PC, et al. Neighbourhood environment, physical activity, quality of life and depressive symptoms in Hong Kong older adults: a protocol for an observational study. BMJ Open. 2016;6(1):e010384.

38. Van Holle V, Van Cauwenberg J, Van Dyck D, Deforche B, Van de Weghe N, De Bourdeaudhuij I. Relationship between neighborhood walkability and older adults' physical activity: results from the Belgian environmental physical activity study in seniors (BEPAS seniors). Int J Behav Nutr Phys Act. 2014;11:110

39. Adams MA, Frank LD, Schipperijn J, Smith G, Chapman J, Christiansen LB, et al. International variation in neighborhood walkability, transit, and recreation environments using geographic information systems: the IPEN adult study. Int J Health Geogr. 2014;13:43.
40. Pruitt LA, Glynn NW, King AC, Guralnik JM, Aiken EK, Miller G, et al. Use of accelerometry to measure physical activity in older adults at risk for mobility disability. J Aging Phys Act. 2008;16(4):416-34.

41. Davis MG, Fox KR, Hillsdon M, Sharp DJ, Coulson JC, Thompson JL. Objectively measured physical activity in a diverse sample of older urban UK adults. Med Sci Sports Exerc. 2011;43(4):647-54

42. Cerin E, Barnett A, Cheung MC, Sit CH, Macfarlane DJ, Chan WM. Reliability and validity of the IPAQ- $L$ in a sample of Hong Kong urban older adults: does neighborhood of residence matter? J Aging Phys Act. 2012;20(4):402-20.

43. Choi L, Ward SC, Schnelle JF, Buchowski MS. Assessment of wear/nonwear time classification algorithms for triaxial accelerometer. Med Sci Sports Exerc. 2012;44(10):2009-16.

44. Aguilar-Farias N, Brown WJ, Peeters GM. ActiGraph GT3X+ cut-points for identifying sedentary behaviour in older adults in free-living environments. Sci Med Sport. 2014;17(3):293-9.

45. Guralnik JM, Simonsick EM, Ferrucci L, Glynn RJ, Berkman LF, Blazer DG, et al. A short physical performance battery assessing lower extremity function: association with self-reported disability and prediction of mortality and nursing home admission. J Gerontol. 1994;49(2):M85-94.

46. Wood SN. Generalised additive models: an introduction with R. 2nd ed. Boca Raton: Chapman and Hall/CRC; 2017.

47. Burnham KP, Anderson DR. Model selection and multimodel inference: a practical information-theoretic approach. 2nd ed. New York: Springer Verlag; 2002.

48. Cervero R, Kockelman K. Travel demand and the 3Ds: density, diversity, and design. Transp Res Part D Transp Environ. 1997;2(3):199-219.

49. Van Cauwenberg J, De Donder L, Clarys P, De Bourdeaudhuij I, Owen N, Dury $S$, et al. Relationships of individual, social, and physical environmental factors with older adults' television viewing time. J Aging Phys Act. 2014; 22(4):508-17.

50. Mackinnon DP, Luecken LJ. How and for whom? Mediation and moderation in health psychology. Health Psychol. 2008;27(2s):S99-s100.

51. R Core Team. R: A language and environment for statistical computing. Vienna, Austria: R Foundation for Statistical Computing; 2017 [Available from: https://www.R-project.org/].

52. Hothorn T, Bretz F, Westfall P. Simultaneous inference in general parametric models. Biom J. 2008;50(3):346-63.

53. Zhang Y, Li C, Eddie Liu Q, Wu W. The socioeconomic characteristics, urban built environment and household car ownership in a rapidly growing city: evidence from Zhongshan, China. J Asian Archit Build Eng. 2018;17(1):133-40.

54. Ding D, Sallis JF, Norman GJ, Frank LD, Saelens BE, Kerr J, et al. Neighborhood environment and physical activity among older adults: do the relationships differ by driving status? J Aging Phys Act. 2014; 22(3):421-31.

55. Hajna S, White T, Panter J, Brage S, Wijndaele K, Woodcock J, et al. Driving status, travel modes and accelerometer-assessed physical activity in younger, middle-aged and older adults: a prospective study of 90810 UK biobank participants. Int J Epidemiol. 2019;48(4):1175-86.

56. Shoham DA, Dugas LR, Bovet $P$, Forrester TE, Lambert EV, Plange-Rhule J, et al. Association of car ownership and physical activity across the spectrum of human development: modeling the epidemiologic transition study (METS). BMC Public Health. 2015;15:173.

57. Garcia-Hermoso A, Martinez-Vizcaino V, Sanchez-Lopez M, Recio-Rodriguez II, Gomez-Marcos MA, Garcia-Ortiz L. Moderate-to-vigorous physical activity as a mediator between sedentary behavior and cardiometabolic risk in Spanish healthy adults: a mediation analysis. Int J Behav Nutr Phys Act. 2015;12:78.

58. Amagasa S, Fukushima N, Kikuchi H, Takamiya T, Odagiri Y, Oka K, et al. Drivers are more physically active than non-drivers in older adults. Int J Environ Res Public Health. 2018;15(6):1094.

59. Moran M, Van Cauwenberg J, Hercky-Linnewiel R, Cerin E, Deforche B, Plaut $P$. Understanding the relationships between the physical environment and physical activity in older adults: a systematic review of qualitative studies. Int J Behav Nutr Phys Act. 2014;11:79.

60. Foley L, Panter J, Heinen E, Prins R, Ogilvie D. Changes in active commuting and changes in physical activity in adults: a cohort study. Int J Behav Nutr Phys Act. 2015;12:161.

61. Mendes de Leon CF, Cagney KA, Bienias JL, Barnes LL, Skarupski KA, Scherr PA, et al. Neighborhood social cohesion and disorder in relation to walking 
in community-dwelling older adults: a multilevel analysis. J Aging Health. 2009;21(1):155-71.

62. Cain KL, Millstein RA, Sallis JF, Conway TL, Gavand KA, Frank LD, et al. Contribution of streetscape audits to explanation of physical activity in four age groups based on the microscale audit of pedestrian streetscapes (MAPS). Soc Sci Med. 2014;116:82-92.

63. Hirsch JA, Winters M, Ashe MC, Clarke P, McKay H. Destinations that older adults experience within their GPS activity spaces in relation to objectively measured physical activity. Environ Behav. 2016;48(1):55-77.

64. Barnett A, Cerin E, Cheung MC, Chan WM. An in-depth pilot study on patterns, destinations, and purposes of walking in Hong Kong older adults. J Aging Phys Act. 2015;23(1):144-52.

65. Winters M, Voss C, Ashe MC, Gutteridge K, McKay H, Sims-Gould J. Where do they go and how do they get there? Older adults' travel behaviour in a highly walkable environment. Soc Sci Med. 2015;133:304-12.

66. Cerin E, Sit CH, Barnett A, Johnston JM, Cheung MC, Chan WM. Ageing in an ultra-dense metropolis: perceived neighbourhood characteristics and utilitarian walking in Hong Kong elders. Public Health Nutr. 2014;17(1):225-32.

67. Mertens L, Van Dyck D, Deforche B, De Bourdeaudhuij I, Brondeel R, Van Cauwenberg J. Individual, social, and physical environmental factors related to changes in walking and cycling for transport among older adults: a longitudinal study. Health Place. 2019:55:120-7.

68. Cheng YH, Chou KL, MacFarlane DJ, Chi I. Patterns of physical exercise and contributing factors among Hong Kong older adults. Hong Kong Med J. 2007;13(4):7-12.

69. Cerin E, Lee KY, Barnett A, Sit CH, Cheung MC, Chan WM. Objectivelymeasured neighborhood environments and leisure-time physical activity in Chinese urban elders. Prev Med. 2013;56(1):86-9.

70. Cerin E, Barnett A, Zhang CJP, Lai PC, Sit CHP, Lee RSY. How urban densification shapes walking behaviours in older community dwellers: a cross-sectional analysis of potential pathways of influence. Int J Health Geogr. 2020;19:14.

71. Davis MG, Fox KR, Hillsdon M, Coulson JC, Sharp DJ, Stathi A, et al. Getting out and about in older adults: the nature of daily trips and their association with objectively assessed physical activity. Int J Behav Nutr Phys Act. 2011:8:116.

72. Rasinaho M, Hirvensalo M, Leinonen R, Lintunen T, Rantanen T. Motives for and barriers to physical activity among older adults with mobility limitations. J Aging Phys Act. 2007;15(1):90-102.

73. Cerin E. Ways of unraveling how and why physical activity influences mental health through statistical mediation analyses. Ment Health Phys Act. 2010;3(2):51-60

74. Cerin E, Mackinnon DP. A commentary on current practice in mediating variable analyses in behavioural nutrition and physical activity. Public Health Nutr. 2009;12(8):1182-8.

75. Handy S. Regional versus local accessibility: implications for nonwork travel. Transp Res Rec. 1993;1400:58-66.

76. Owen N, Sugiyama T, Koohsari MJ, De Bourdeaudhuij I, Hadgraft N, Oyeyemi A, et al. Associations of neighborhood environmental attributes with adults' objectively-assessed sedentary time: IPEN adult multi-country study. Prev Med. 2018;115:126-33.

77. Cleland C, Reis RS, Ferreira Hino AA, Hunter R, Fermino RC, Koller de Paiva $\mathrm{H}$, et al. Built environment correlates of physical activity and sedentary behaviour in older adults: a comparative review between high and lowmiddle income countries. Health Place. 2019;57:277-304.

78. Cui Y, Ge SS. Autonomous vehicle positioning with GPS in urban canyon environments. IEEE Trans Rob Autom. 2003;19(1):15-25

79. Cerin E, Nathan A, Choi WK, Ngan W, Yin S, Thornton L, et al. Built and social environmental factors influencing healthy behaviours in older Chinese immigrants to Australia: a qualitative study. Int J Behav Nutr Phys Act. 2019:16(1):116

\section{Publisher's Note}

Springer Nature remains neutral with regard to jurisdictional claims in published maps and institutional affiliations.

\section{Ready to submit your research? Choose BMC and benefit from:}

- fast, convenient online submission

- thorough peer review by experienced researchers in your field

- rapid publication on acceptance

- support for research data, including large and complex data types

- gold Open Access which fosters wider collaboration and increased citations

- maximum visibility for your research: over $100 \mathrm{M}$ website views per year

At BMC, research is always in progress.

Learn more biomedcentral.com/submissions 